\title{
Characterization of Vitrocrystalline Foams Produced from Discarded Glasses and Recycled Polystyrene Spheres
}

\author{
Andre Luiz Paiva ${ }^{a}$, Elisângela Guzi de Moraes ${ }^{a}$, Naiane Paiva Stochero ${ }^{a}$, Antonio Pedro Novaes de Oliveira ${ }^{a}$ \\ ${ }^{a}$ Laboratório de Materiais Vitrocerâmicos - VITROCER, Departamento de Engenharia Mecânica, \\ Universidade Federal de Santa Catarina - UFSC, Florianópolis, SC, Brazil
}

Received: December 15, 2016; Revised: July 19, 2017; Accepted: September 17, 2017

\begin{abstract}
In this work, discarded soda-lime glasses (from glass bottles) and recycled polystyrene (PS) spheres $\left(\mathrm{d}_{50}<300 \mu \mathrm{m}\right)$ were successfully converted into vitrocrystalline foams for thermal insulation applications. Physical and chemical properties of the selected and prepared raw materials (wastes) were characterized. Batches containing well mixed glass powder $\left(\mathrm{d}_{50}<5 \mu \mathrm{m}\right)$, PS spheres $(10-80$ vol.\% and PVA ( 8 vol.\% ) were obtained and uniaxially pressed at $20 \mathrm{MPa}$. The obtained powder compacts were dried in air for $24 \mathrm{~h}$ and then fired at different temperatures $\left(850\right.$ to $\left.900{ }^{\circ} \mathrm{C}, 10{ }^{\circ} \mathrm{C} / \mathrm{min}\right)$ for 30 min. Vitrocrystalline foams with interconned cells sizes between 86 and $815 \mu \mathrm{m}$, homogeneously distributed in a crack free matrix, were characterized from the point of view of their typical physical, chemical, morphological and mechanical properties. The results showed that it is possible to obtain vitrocrystalline foams with porosities up to $89 \%$ and compressive strength varying from 4 to $25 \mathrm{MPa}$.
\end{abstract}

Keywords: Vitrocrystalline foams, bottle glasses, pore forming agents, polystyrene spheres, thermal insulation.

\section{Introduction}

Porous ceramics can be produced from many different materials, such as alumina, mullite, silicon carbide, zirconia and hydroxyapatite. Some recent researches have shown the processing advantages of the using glasses as base materials for production of porous ceramics ${ }^{1-3}$.

Glasses are $100 \%$ recyclable, different from other materials; their structures are fully recovered when reprocessed. Furthermore, the recovery of waste glass bottles is a strategic tool in terms of energy saving. It is estimated that in order to produce $1 \mathrm{~kg}$ of glass, 4,500 $\mathrm{kJ}$ are needed, and around $11 \%$ of the energy harnessed through recycling ${ }^{4}$.

Glass foams have a unique combination of important properties: They are lightweight, rigid, compression-resistant, thermally insulating, freeze-tolerant, nonflammable, chemically inert and nontoxic, among others ${ }^{5}$. These materials are characterized by high porosity $(>60 \%)$ and can be produced with open, and/or close structure ${ }^{6}$. The most commonly accepted concept regarding pore size is defined by IUPAC ${ }^{7}$, which classifies them in micro $(<2 \mathrm{~nm})$, meso $(2-50 \mathrm{~nm})$ or macroporous $(>50 \mathrm{~nm}$ ). The pore size distribution and quantity determine specific properties, such as low density and thermal conductivity, high surface area, permeability and chemical and thermal stabilities ${ }^{1,8,9}$. These properties make glass foam structural blocks an excellent product for applications such as: insulation of roofs, walls, floors and ceilings in hot or cold conditions ${ }^{1}$.

The production of porous ceramics generally consists in three steps: preparation of a ceramic powder suspension,

*e-mail: lisguzi@gmail.com followed by forming and subsequent heat treatment (firing). Several processing techniques have been used for produce porous structures such as replica, gelcasting, direct foaming, incorporation of pore forming agents (sacrificial template $)^{1,10}$. This last one consists in the incorporation of pore forming agents in the ceramic bodies, which are removed during the firing step. The pore size is directly associated with the specific characteristics of each pore forming agent ${ }^{10,11}$. In fact, synthetic (polymers) and / or natural (vegetal and mineral residues $)^{12}$ may be used as pore formers.

Researches have demonstrated that different waste materials can be used as alternative sources of pore forming agents $^{6,12}$. Polymers used by packaging industry, such as Styrofoam, are characterized as extensive polluters due to the volume of tailing. Polystyrene (PS) is among the most used polymeric materials (annual growth of $6.6 \%$ ) $^{13}$ and most of its current recycling methods produces undesirable byproducts. In addition, technologycal issues as high viscosity and the low heat transfer rates of the molten PS, limits the commercial application of its recycling process. Alternatively, recycling through the addition of the styrofoam packaging to the polymerization reaction presents a viable alternative to reduce raw material and energy costs ${ }^{13,14}$.

In this context, vitrocrystalline foams with optimized properties were developed by sacrificial template using discarded glass bottles and recycled polystyrene spheres, as pore forming agent in different volumetric fractions (10 - 80 vol.\%) envisaging thermal and acoustic insulation applications in building systems that require a suitable set of properties as thermal conductivity, porosity and mechanical strength. 


\section{Materials and Methods}

The process for fabricating the vitrocrystalline foams is given by the flowchart in Figure 1, as described in detail in the following sections.

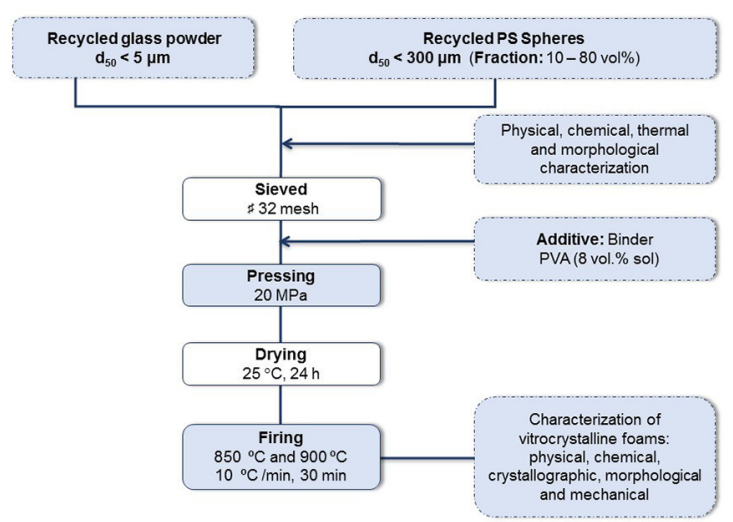

Figure 1. Flowchart for production of vitrocrystalline foams by sacrificial template processes.

\subsection{Raw materials preparation and characterization}

In this work, discarded glass bottles of different colors (clear, green, brown), collected in commercial establishments in Florianópolis (SC) city - Brazil) were washed and dried in a dryer at $100{ }^{\circ} \mathrm{C} \pm 15^{\circ} \mathrm{C}$ for $24 \mathrm{~h}$. The bottles were, initially, broken with aid of a hammer and the fragments were crushed in a hammer mill (SERVITECH CT-058) to average size $<1 \mathrm{~mm}$. The resulting powder of each glass color (in the same proportions) was dry mixed in a planetary mill (SERVITECH CT-242) containing alumina grinding media for $1 \mathrm{~h}$ at $150 \mathrm{rpm}$ and then sieved to yield a powder of particle size $<45 \mu \mathrm{m}$. Subsequently, the obtained powder was wet milled for $48 \mathrm{~h}$ in a rolling jar (CIENLAB CE-500/D, at $150 \mathrm{rpm}$, glass powder:water; 4:6).

The average particle size distribution of the recycled glass powder and PS spheres were determined using a laser scattering particle size analyzer (Master Sizer 3000, Malvern). The particle morphology was evaluated by a scanning electron microscopy (SEM), JEOL JSM (model 6390LV). The true density $\left(\rho_{t}\right)$ of the recycled glass powder and PS spheres was determined by using a helium pycnometer (Quantachrome Ultra Pycnometer 1000). Chemical composition of the glasses was evaluated by X-ray fluorescence spectroscopy (FRX, Philips PW 2400) and the amorphous structure of the as prepared glass powder and crystalline phases of the vitrocrystalline foams containing $70 \mathrm{vol} . \%$ of PS spheres, fired at diferent temperatures $\left(850\right.$ and $\left.900{ }^{\circ} \mathrm{C}\right)$ were determined by X-ray diffractometry, (Philips X'pert - with $\mathrm{Cu} \mathrm{K} \alpha, 40$ $\left.\mathrm{kV}, 40 \mathrm{~mA}, 0.05^{\circ}, 2 \mathrm{~s}\right)$. Linear shrinkage of glass compacts, as well as a composition containing 5 vol.\% of PS spheres, was evaluated using an optical dilatometer (Expert System Solution Misura ODHT) at a heating rate of $10^{\circ} \mathrm{C} / \mathrm{min}$, in the temperature range of 25 to $1100^{\circ} \mathrm{C}$, and static natural air. The samples were manually pressed using a matrix to obtain cylinders with nominal diameter of $2 \mathrm{~mm} \times 3 \mathrm{~mm}$ (height).

Polystyrene spheres (PS) were recycled according to the procedure reported by Machado et al. ${ }^{13}$, briefly described as following: a borosilicate glass reactor (1L), provided with agitation system (up to $4000 \mathrm{rpm}$ ) and Nitrogen flow, was used in a aqueous suspension polymerization process. Styrene monomer ( 90 vol.\%) and initiators (benzoyl peroxide; tertbutyl peroxide); and poly (vinyl pyrrolidone), as stabilizer agent, Styrofoam packing powder (previously milled, 10 vol.\%), as recycled part used in substitution of the styrene monomer, was added to this system. The temperature was keeped constant at $90^{\circ} \mathrm{C}$ for $6 \mathrm{~h}$, and additionaly, at $120^{\circ} \mathrm{C}$ for $3 \mathrm{~h}$ for residual monomer consumption. The PS spheres were kindly provided by LMP/UFSC. The thermal behaviour of PS spheres was determined by differential thermal and thermogravimetric analysis (DTA-TGA, TA Instruments Q600 SDT) at $10{ }^{\circ} \mathrm{C} / \mathrm{min}$ with a flow of synthetic air of $10 \mathrm{~cm}^{3} / \mathrm{min}$.

\subsection{Foams preparation and characterization}

Recycled PS spheres $\left(\mathrm{d}_{50}<300 \mu \mathrm{m}, \rho=1.07 \mathrm{~g} / \mathrm{cm}^{3}\right)$ were mixed with the glass powder in different proportions (10 - 80 vol.\%), then manually homogenized and passed through a sieve $(<500 \mu \mathrm{m})$, in order to form a uniform layer of powder on the surface of the spheres enhancing particle packing. The prepared compositions were uniaxially pressed (hydraulic press Bovenau P10 ST) at $20 \mathrm{MPa}$, with the addition of a binder (PVA 8 vol.\% sol) to obtain disks with nominal diameter of $30 \mathrm{~mm}$ x $15 \mathrm{~mm}$ (thickness). After air-drying for $24 \mathrm{~h}$, the powder compacted bodies were fired in oxidizing atmosphere at 850 and $900{ }^{\circ} \mathrm{C}\left(30 \mathrm{~min} ; 10^{\circ} \mathrm{C} /\right.$ min heating rate).

Samples containing 70 vol.\% of PS spheres were selected because these samples presented the best microstructureproperty relations from green porosity point of view. These samples were used to study the influence of temperature on the formation of crystalline phases.

In order to investigate the influence of volumetric fraction of PS spheres, on the morphology and cellular structure (porosity and pore size distribution) of the foams, as well as the compressive strength, the vitrocrystalline foams containing 10 to 80 vol.\% of PS spheres were characterized from the point of view of their typical physical, morphological and mechanical properties.

The true density $\left(\rho_{t}\right)$ of fired vitrocrystalline foam (crushed and milled cell walls) was determined by using a helium pycnometer (Quantachrome Ultra Pycnometer 1000). The apparent density $\left(\rho_{a}\right)$ of fired foam samples was determined by relating their geometrical measurements, obtained using a caliper (Mitotoyo, accuracy $\pm 0.01 \mathrm{~mm}$ ), and their masses (Shimadzu AX200 at $0.001 \mathrm{~g}$ ). The relative density $\left(\rho_{r}\right)$ was calculated, relating the apparent densities and the true 
densities of the samples. From measurements of geometrical and true densities the porosity $(\varepsilon)$ of fired vitrocrystalline foams was calculated according to Equation 1.

$$
\varepsilon=\left(1-\frac{\rho_{a}}{\rho_{t}}\right) \times 100
$$

The morphology and cellular structure (pore size distribution) of the fired foams was investigated by scanning electron microscopy (SEM, JEOL JSM - model 6390LV). The linear intercept method (ASTM E112-12) was used to estimate the pore size distribution from the micrographs using an image analysis program (Axio Vision LE). The average values were obtained considering stereological relations (ASTM D3576-98).

The compressive strength of the fired vitrocrystalline foams was measured on samples with nominal dimensions of 10x10x10 mm using a universal testing machine (EMIC, model DL 2000; $1.0 \mathrm{~mm} / \mathrm{min}$ cross-head speed), according to ASTM C133-97. Three to five specimens cut from larger 30 $\mathrm{x} 15 \mathrm{~mm}$ disks, were tested for each sample. It is important to mention that EVA sheets (ethylene-vinyl acetate) of $2 \mathrm{~mm}$ thickness were placed in the interface between sample faces and cell load in order to assure homogeneous load transfer and compensate for any surface irregularities.

\section{Results and Discussion}

The particle size distribution of the glass powder is presented in Figure 2 for different milling processes. After the first step of dry milling using a planetary mill, a wide particle size distribution $\left(\mathrm{d}_{10}=1.8<\mathrm{d}_{50}=9.3<\mathrm{d}_{90}=27.6\right.$ $\mu \mathrm{m}$ ) is observed (Figure 2 (a)). After $24 \mathrm{~h}$ of wet milling using a rolling jar, the resulting powder exhibited sizes ranging from $\mathrm{d}_{10}=1.3$ to $\mathrm{d}_{90}=15.9 \mu \mathrm{m}$ showing a reduction on the mean particle size, $d_{50}=5.3 \mu \mathrm{m}$, approximately $43 \%$, related to the initial size, characterizing thus a relatively narrower particle size distribution profile according to the black curve in Figure 2 (a). It is remarkable that the comminution after $48 \mathrm{~h}$ of wet milling is not so significant (from $\mathrm{d}_{10}=1.1$ to $\left.\mathrm{d}_{90}=11.0 \mu \mathrm{m}\right), \mathrm{d}_{50}=3.9 \mu \mathrm{m}$, only yielding a $26 \%$ reduction with respect to the average size upon $24 \mathrm{~h}$ (see dark gray curve in Figure 2 (a)). Effectively, narrower particle size distribution allows a better control of homogenization and pressing processes favoring the reduction of density of powder compacted bodies and firing temperatures.

Figure 2 (b) shows the morphology of the particles and agglomerates generated after $48 \mathrm{~h}$ of wet milling. The theoretical density of the glass powder after wet milling (48 h) determined by gas pycnometry, was $2.47 \mathrm{~g} / \mathrm{cm}^{3}$.

According to the literature, the initial particle size and load volume in the mill are determining factors to improve grinding efficiency and should be taken into account to obtain powders with suitable size for colloidal processing, for example ${ }^{15,16}$.

The particle size distribution of the PS spheres, measured using a laser scattering particle size analyzer exhibited sizes ranging from $d_{10}=217 \mu \mathrm{m}_{\text {to }} \mathrm{d}_{90}=437 \mu \mathrm{m}$, in good agreement with the distribution of measured size by image analysis where the values ranging from $\mathrm{d}_{10}=255 \pm 3<\mathrm{d}_{50}$ $=355 \pm 3<\mathrm{d}_{90}=471 \pm 6 \mu \mathrm{m}$. The theoretical density of PS spheres determined by gas pycnometry, was $1.07 \mathrm{~g} / \mathrm{cm}^{3}$.

Chemical compositions of discarded glass bottles of different colors (clear, green, brown) and of their mix are shown in Table 1. From Table 1 it can be seen that the glass bottles used in this work belong to the silica-soda-lime glass family such that the major and main differences in composition may be related to the chromophores oxides, particularly iron oxide $\left(\mathrm{Fe}_{2} \mathrm{O}_{3}\right)$, which, as expected, increases when the coloration of the glasses changes from white/clear to green and brown. As the applications envisaged in this
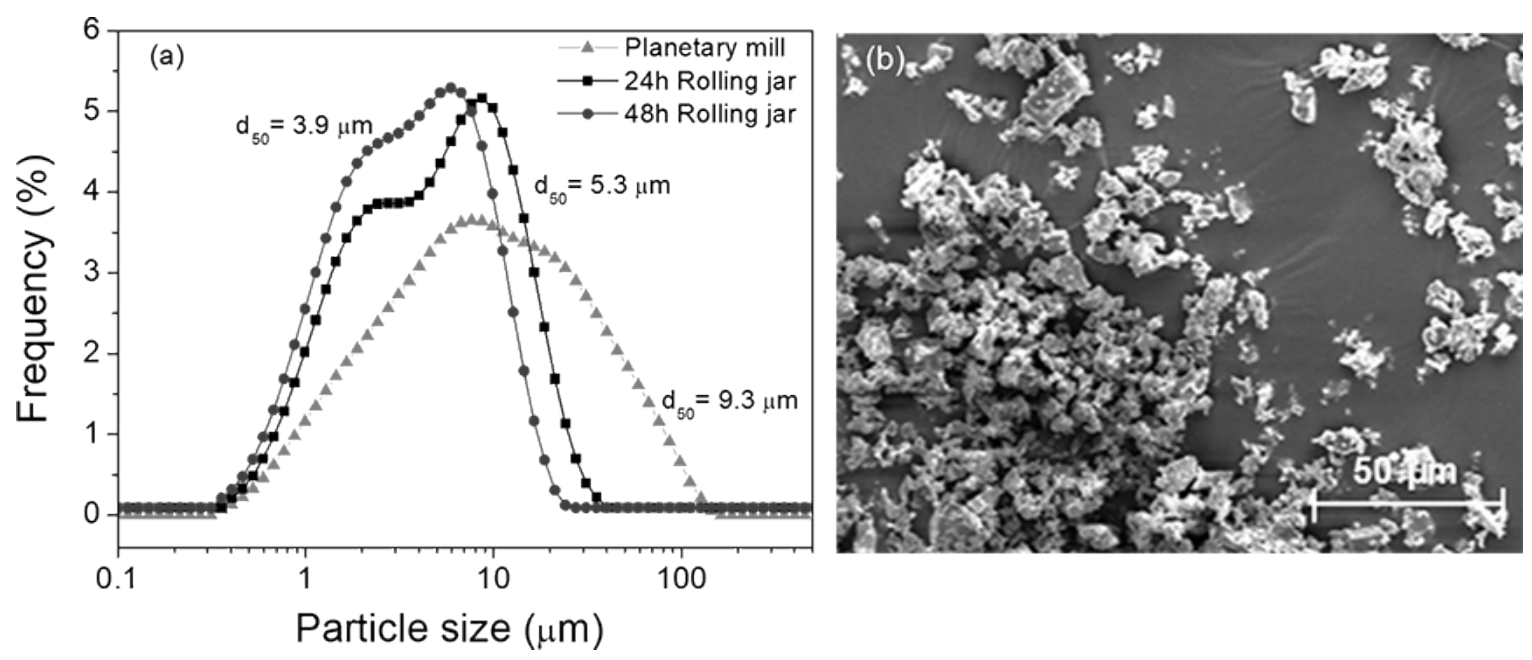

Figure 2. (a) Particle size distribution curves of the glass powders obtained from different milling processes exhibiting their respectives $\mathrm{d}_{50}$ values; (b) SEM micrograph of the glass powder resulting from the final milling $(48 \mathrm{~h})$. 
Table 1. Chemical composition of the investigated glasses determined by FRX analysis.

\begin{tabular}{cccccccccccccc}
\hline \multicolumn{10}{c}{ Constituent oxides (wt.\%) } \\
\hline Glasses & $\mathrm{SiO}_{2}$ & $\mathrm{Al}_{2} \mathrm{O}_{3}$ & $\mathrm{Fe}_{2} \mathrm{O}_{3}$ & $\mathrm{Na}_{2} \mathrm{O}$ & $\mathrm{CaO}$ & $\mathrm{MgO}$ & $\mathrm{K}_{2} \mathrm{O}$ & $\mathrm{TiO}_{2}$ & $\mathrm{P}_{2} \mathrm{O}_{5}$ & $\mathrm{Cr}_{2} \mathrm{O}_{3}$ & $\mathrm{BaO}$ & $* \mathrm{~L} . \mathrm{O} . \mathrm{I}$ \\
Clear & 71.25 & 1.77 & 0.21 & 13.67 & 11.59 & 0.50 & 0.22 & $<0.05$ & $<0.05$ & $<0.1$ & 0.13 & 0.46 \\
Green & 71.06 & 1.99 & 0.44 & 13.74 & 10.76 & 0.84 & 0.31 & $<0.05$ & $<0.05$ & 0.28 & 0.13 & 0.35 \\
Brown & 71.14 & 1.73 & 0.51 & 13.62 & 10.92 & 0.90 & 0.36 & $<0.05$ & $<0.05$ & $<0.1$ & 0.08 & 0.54 \\
Mixture & 71.1 & 1.84 & 0.39 & 13.71 & 11.11 & 0.74 & 0.30 & $<0.05$ & $<0.05$ & 0.12 & 0.08 & 0.51 \\
\hline
\end{tabular}

*L.O.I.: Loss of Ignition

work mainly contemplate panels for thermal insulation used in buildings in general, no aesthetic requirements in terms of a specific color are required.

From the thermogravimetric analysis, dash curve in Figure 3 (a), the thermo-oxidative behavior of the PS spheres under dry air flow is shown. The experiments were performed from room temperature to $1000{ }^{\circ} \mathrm{C}$. The PS spheres have three stages of thermal degradation: the first one occurs at $180^{\circ} \mathrm{C}$ due to loss of molecular weight by scission of weak bonds, according to Beach et al. ${ }^{17}$; the second and more significant may be attributed to the burning of the organic part (benzaldehyde and acetophenones formed by the $\mathrm{CH}_{2}$ decomposition groups and benzyl ${ }^{18}$, occurring between 300 and $400{ }^{\circ} \mathrm{C}$ ). An additional step appears to occur between 400 and $575^{\circ} \mathrm{C}$, as a result of complex processes involving oxygen, products of PS degradation and various species of carbon oxides that arises from the thermo-oxidative degradation $^{19}$. This interpretation is consistent with the DTA, black curve in Figure 3 (a), which shows a steady increase of temperature followed by an endothermic peak at $450{ }^{\circ} \mathrm{C}$ related to its volatilization ${ }^{20}$. The significant weight loss observed in the second stage leads to the formation of gas and hence increases the porosity of the vitrocrystalline foam.

Figure 3 (b) shows the linear shrinkage curves of a glass powder compact and of a glass composition containing 5 vol.\% of PS spheres. According to the dilatometric curves of glass compacts, there is no significant changes in the dimensions up to about $600{ }^{\circ} \mathrm{C}$ (near to the glass transition temperature,
$\mathrm{Tg}$, see inserted images in detail). However, above $600{ }^{\circ} \mathrm{C}$ up to about $715^{\circ} \mathrm{C}$, a fast densification process (at high rates) occurs, which continues at lower rates up to $\sim 830^{\circ} \mathrm{C}$. A slight increase in volume is observed from above $900^{\circ} \mathrm{C}$, as a result of the viscous liquid phase formation that results from the melting of the crystalline phases present (at $950^{\circ} \mathrm{C}$, see inserted half-sphere images in detail). The presence of crystalline phases is evidenced by crystalline peaks on XRD pattern, as will be discussed further in Figure 4.

The dilatometric curve of glass compacts containing 5 vol.\% of PS spheres shows the same behaviour as explained above. It is noteworthy that there is an expansion of $5 \%$ at temperatures from $\sim 180$ to $200{ }^{\circ} \mathrm{C}$, as a result of onset of thermal degradation and loss of molecular weight of polystyrene (PS), showing good agreement with TGA curve. Furthermore, we added images of the probe evolution during the test. It is interesting to note that we tested the glass compact with 5 vol.\% of PS sphere, because with the increasing of PS concentration the sample collapses even at low temperatures and once it is an optical measurement, the test is stopped.

Figure 4 show XRD diffraction patterns of the amorphous structure of the glass powder (as prepared) and crystalline structure of the vitrocrystalline foams containing $70 \mathrm{vol} . \%$ of PS spheres, fired at different temperatures $\left(850\right.$ and $\left.900{ }^{\circ} \mathrm{C}\right)$ for $30 \mathrm{~min}$. The main peaks were attributed to the crystalline phases of devitrite (JCPDS-00-023-0671) and cristobalite (JCPDS-01-076-0939).
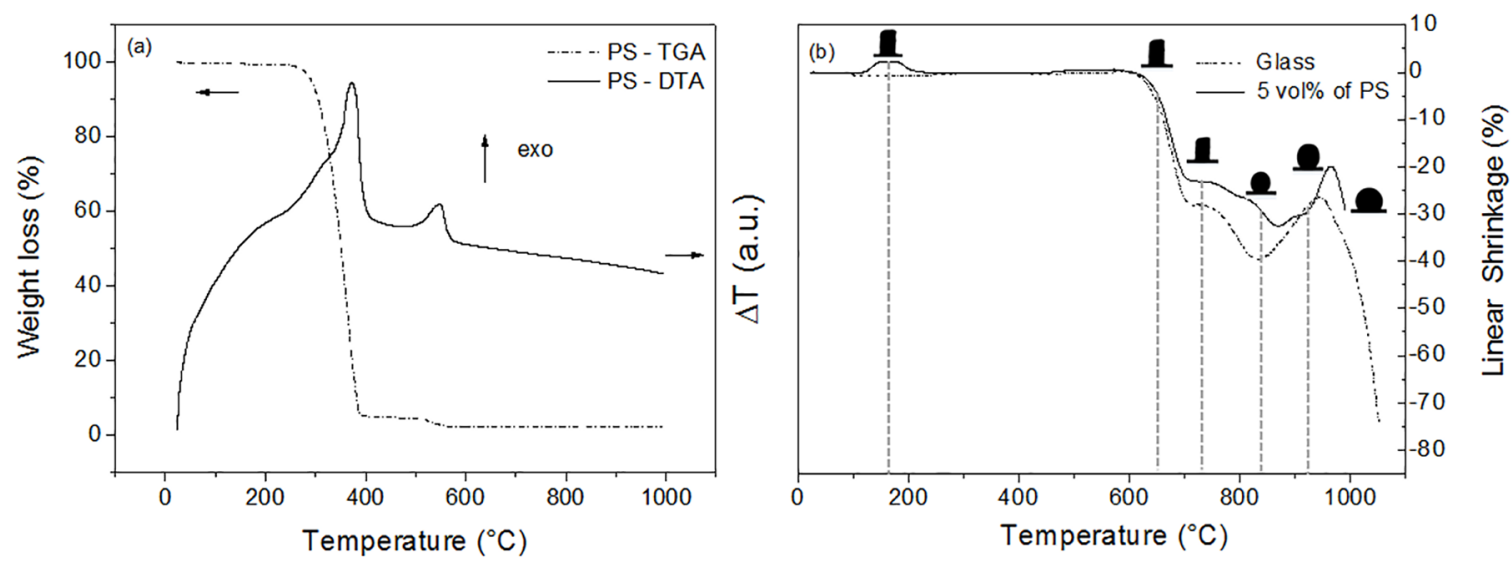

Figure 3. (a) DTA/TGA curves of PS spheres and (b) Linear dimensional change curve obtained by optical dilatometry of compacted bodies of glass powder and a glass composition containing 5 vol.\% of PS spheres. 


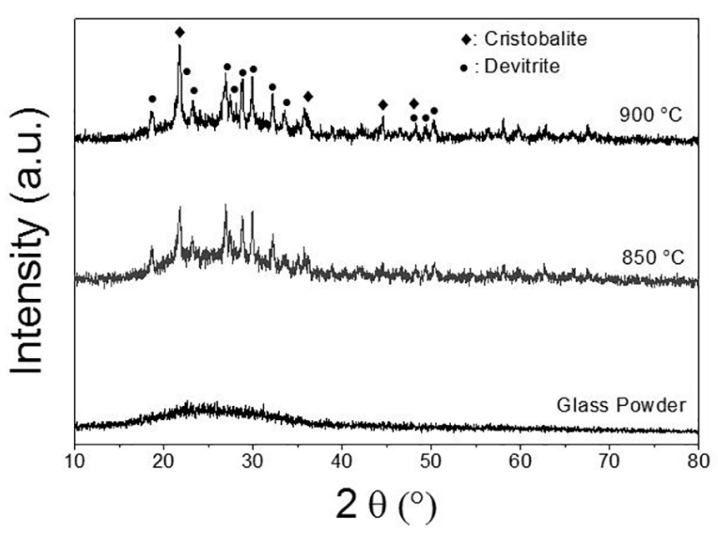

Figure 4. XRD patterns of the amorphous structure of the glass powder (as prepared) and crystalline structure of the vitrocrystalline foams containing 70 vol.\% of PS spheres, fired at different temperatures $\left(850\right.$ and $900{ }^{\circ} \mathrm{C}$ ) for $30 \mathrm{~min}$. $\$$ : Cristobalite; $\bullet$ : devitrite.

Figure 5 shows the influence of the volume fraction of PS (from 10 to $80 \mathrm{vol} . \%$ ) on the porosity of the vitrocrystalline foams fired at different temperatures for $30 \mathrm{~min}$. Broad porosity can be achieved ranging from $67 \pm 2 \%$ up to $89 \pm 3 \%$, and from $63 \pm 2 \%$ up to $85 \pm 3 \%$, for vitrocrystalline foams fired at $850{ }^{\circ} \mathrm{C}$ and $900{ }^{\circ} \mathrm{C}$, respectively.

Note that vitrocrystalline foams fired at $850{ }^{\circ} \mathrm{C}$ exhibit higher porosities ranging from 67 to $89 \%$ caused by the expansion resultant of the softening of the glass before melting of the crystalline phases present, as evidenced in Figure 3 (b), when compared with that one fired at $900{ }^{\circ} \mathrm{C}$ (63 to $85 \%$ ).

Figure 6 shows SEM micrographs of the typical morphology and cellular structure of pores formed in foam samples fired at $850{ }^{\circ} \mathrm{C}$ for $30 \mathrm{~min}$. Figure 6 (a) shows

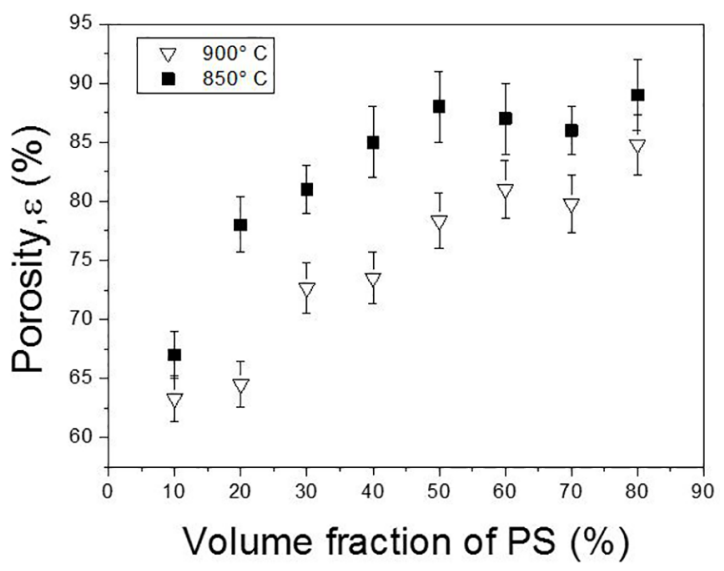

Figure 5. Influence of the volume fraction of PS spheres (from 10 to $80 \mathrm{vol} . \%$ ) on the porosity of the vitrocrystalline foams fired at different temperatures $\left(850\right.$ and $\left.900{ }^{\circ} \mathrm{C}\right)$ for $30 \mathrm{~min}$. in detail the morphology of the PS spheres exhibiting a narrow size distribution $\left(\mathrm{d}_{10}=255 \pm 3<\mathrm{d}_{50}=355 \pm 3<\mathrm{d}_{90}\right.$ $=471 \pm 6 \mu \mathrm{m}$ ). Figure $6(\mathrm{~b}-\mathrm{i})$, reports the structure (pore size distribution) of glass foams containing 10 to $80 \mathrm{vol} . \%$ of PS spheres. From Figure 6 it can be seen a network of spherical pore morphology homogeneously distributed in a crack free matrix characterized by the increasing of cell sizes (from $86 \pm 4.5 \mu \mathrm{m}$ to $815 \pm 13 \mu \mathrm{m}$ ) when varying the volume fraction of pore forming. The average pore size distribution and total porosity of the vitrocrystalline foams are summarized in Table 2.

It is noteworthy that, vitrocrystalline foams containing 10 vol.\% of PS, Figure 6 (b), exhibit small pores (smaller than PS spheres), that can be related with the elimination of the volatile species (gaseous decomposed species from PS) by diffusion between the interstices of glass powder loose packed, and also due to the presence of moisture in the glass powder ${ }^{21}$. With the increasing of the temperature (at high heating rates), it generates steam (water vapor), and consequently, the gas bubbles will be trapped inside the glass matrix.

It can be seen from Table 2 that is possible to tailor the porosity and pore morphology of the final vitrocrystalline foams. The relative sizes, however, may be associated with the aggregation of two or more spheres due to the high volume fraction of sacrifical agents and/or the diffusion of gases from the compacts.

The compressive strength as a function of total porosity is reported in Figure 7 for vitrocrystalline foam samples fired at $850{ }^{\circ} \mathrm{C}$ for $30 \mathrm{~min}$.

The compressive strength values of the obtained vitrocrystalline foams increased from $4 \pm 0.5$ to $25 \pm 0.9$ $\mathrm{MPa}$, when the porosity decreased from $89 \pm 3.0$ to 67 $\pm 2.0 \%$. Furthermore, with the increase of the volume fraction of PS spheres from 50 to 80 vol.\%, no significant difference was observed with respect of porosity. However, the vitrocrystalline foams develop a more interconnected structure, and consequently the pore walls have higher porosity. The pore sizes are progressively larger by the increasing of volume fraction of PS spheres and the struts become thinner, which affects the mechanical strength.

Nevertheless, the strength values for these samples were higher than those glass foams with similar composition and total porosity produced with graphite (waste from electrodes of electric melting furnaces for steel) as pore forming agent (less than $<20 \mathrm{MPa})^{22}$.

Porosity is essential for determining vitrocrystalline foam performance. Mechanical strength generally decreases with increasing porosity, same for thermal conductivity, so that a compromise must be found when glass foams are intended to be used as a thermal insulator. 

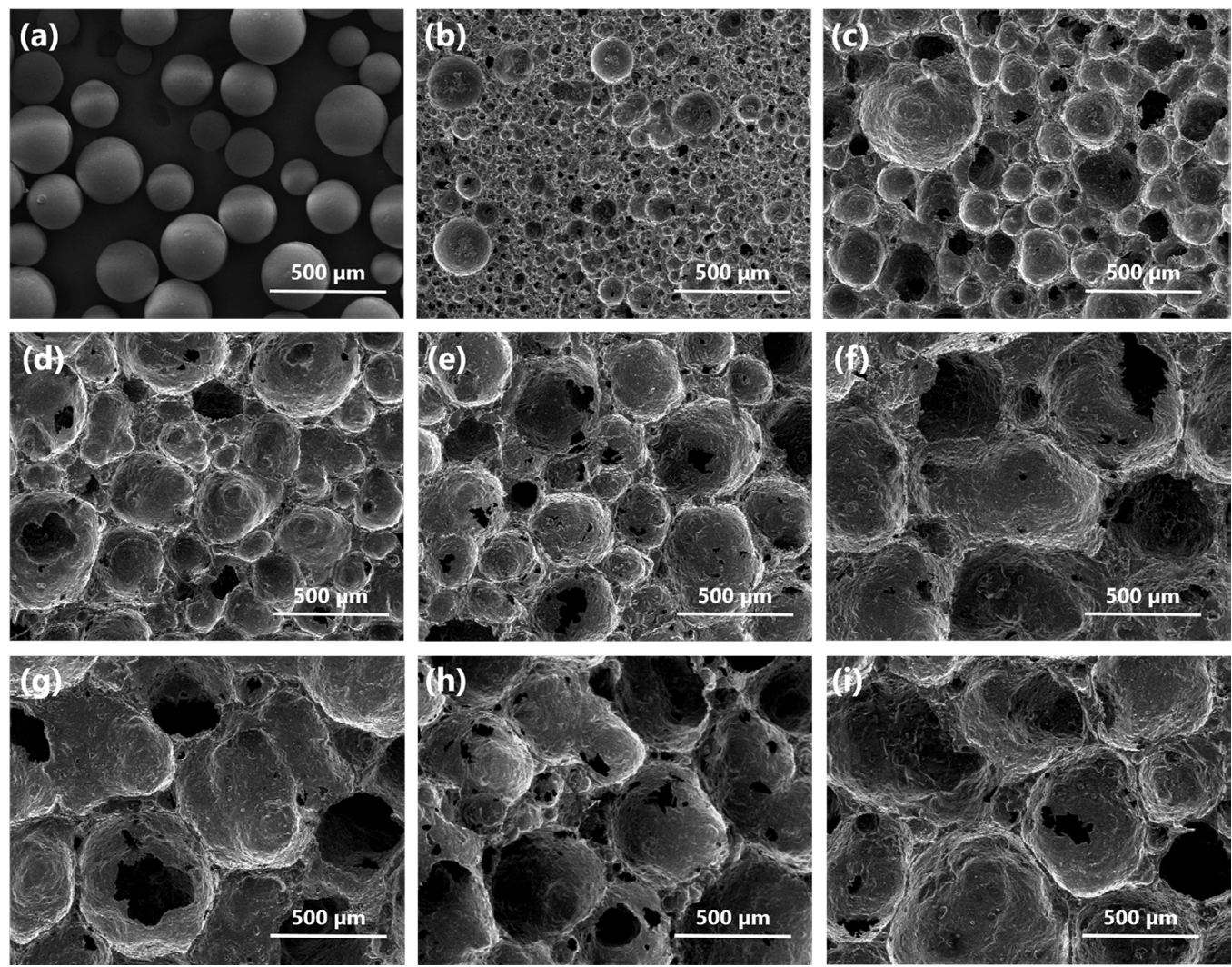

Figure 6. SEM micrographs of the typical morphology and cellular structure of pores formed in vitrocrystalline foams fired at $850{ }^{\circ} \mathrm{C}$ for $30 \mathrm{~min}$ resulting from different volume fraction of PS spheres incorporation. (a) PS spheres morphology of the depicted in detail. Morphology of glass foams containing: (b) 10; (c) 20; (d) 30; (e) 40; (f) 50; (g) 60; (h) 70 and (i) 80 vol.\% of PS.

Table 2. Summary of the average pore size distribution and total porosity of vitrocrystalline foams fired at $850{ }^{\circ} \mathrm{C}$ for $30 \mathrm{~min}$.

\begin{tabular}{ccccccccc}
\hline & \multicolumn{8}{c}{ Volume fraction of PS spheres (vol.\%) } \\
\hline Pore Size ( $\boldsymbol{\mu m})$ & $\mathbf{1 0}$ & $\mathbf{2 0}$ & $\mathbf{3 0}$ & $\mathbf{4 0}$ & $\mathbf{5 0}$ & $\mathbf{6 0}$ & $\mathbf{7 0}$ & $\mathbf{8 0}$ \\
$\mathbf{d}_{10}$ & $55 \pm 4$ & $162 \pm 5$ & $150 \pm 4$ & $264 \pm 3$ & $328 \pm 3$ & $393 \pm 7$ & $356 \pm 7$ & $508 \pm 6$ \\
$\mathbf{d}_{50}$ & $86 \pm 5$ & $255 \pm 6$ & $254 \pm 3$ & $445 \pm 2$ & $636 \pm 4$ & $698 \pm 9$ & $566 \pm 7$ & $815 \pm 13$ \\
$\mathbf{d}_{90}$ & $166 \pm 5$ & $415 \pm 4$ & $432 \pm 4$ & $734 \pm 2$ & $1035 \pm 4$ & $1040 \pm 9$ & $838 \pm 10$ & $1274 \pm 5$ \\
Porosity (\%) & $67 \pm 2$ & $78 \pm 2$ & $81 \pm 2$ & $85 \pm 3$ & $88 \pm 3$ & $87 \pm 3$ & $86 \pm 2$ & $89 \pm 3$ \\
\hline
\end{tabular}

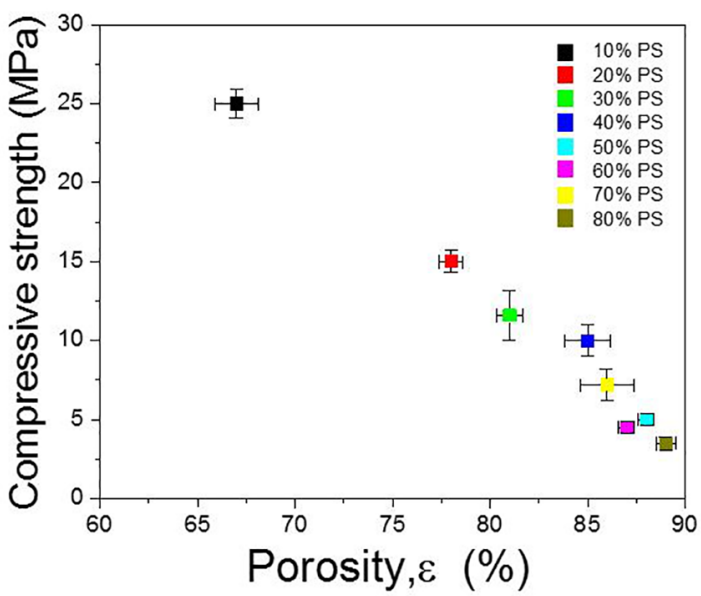

Figure 7. Compressive strength of fired $\left(850^{\circ} \mathrm{C} / 30 \mathrm{~min}\right)$ vitrocrystalline foams as a function of porosity.

\section{Conclusion}

Vitrocrystalline foams with a suitable combination of interconnected porosity ( 67 up to $89 \%$ ) and pore sizes (ranging from $86 \mu \mathrm{m}$ to $815 \mu \mathrm{m}$ ), homogeneously distributed in a crack free matrix and with compressive strength varying from 4 to $25 \mathrm{MPa}$ could be successfully produced from a mixture containing soda-lime glass powders (waste glass bottles) and recycled PS spheres (10 to 80 vol.\%) as pore forming agents.

\section{Acknowledgment}

The authors are grateful to CAPES, FAPESC/CNPq (PRONEX T.O. N. 17431/2011-9) and PIBIC/CNPq-UFSC for funding this work. 


\section{References}

1. Scheffler M, Colombo P, eds. Cellular Ceramics: Structure, Manufacturing, Properties and Applications. Weinheim: WILEY-VCH; 2005.

2. Zhu X, Jiang D, Tan S. Preparation of silicon carbide reticulated porous ceramics. Materials Science and Engineering: A. 2002;323(1-2):232-238.

3. Rouquerol J, Avnir D, Fairbridge CW, Everett DH, Haynes JM, Pernicone N, et al. Recommendations for the characterization of porous solids (Technical Report). Pure and Applied Chemistry. 1994;66(8):1739-1758.

4. Alves OL, Gimenes IF, Mazalli IO. Vidros. Cadernos Temáticos Química Nova na Escola - Novos Materiais. 2001;Ed Esp:9-20.

5. Colombo P. Conventional and novel processing methods for cellular ceramics. Philosophical Transactions of the Royal Society A: Mathematical, Physical and Engineering Sciences. 2006;364(1838):109-124.

6. Bernardo E, Cedro R, Florean M, Hreglich S. Reutilization and stabilization of wastes by the production of glass foams. Ceramics International. 2007;33(6):963-968.

7. Sing KSW, Everett DH, Haul RAW, Moscou L, Pierotti RA, Rouquerol J, et al. Reporting physisorption data for gas/solid systems with special reference to the determination of surfacearea and porosity (Recommendations 1984). Pure and Applied Chemistry. 1985;57(4):603-619.

8. Zeschky J, Goetz-Neunhoeffer F, Neubauer J, Lo SJ, Kummer B, Scheffler M, et al. Preceramic polymer derived cellular ceramics. Composites Science and Technology. 2003;63(16):2361-2370.

9. Barg S, Soltmann C, Andrade M, Koch D, Grathwohl G. Cellular ceramics by direct foaming of emulsified ceramic powder suspensions. Journal of the American Ceramic Society. 2008;91(9):2823-2829.

10. Studart AR, Gonzenbach UT, Tervoort E, Gauckler LJ. Processing Routes to Macroporous Ceramics: A Review. Journal of the American Ceramic Society. 2006;89(6):1771-1789.

11. Romano RCO, Pandolfelli VC. Production and properties of porous ceramics obtained by foam addition technique. Cerâmica. 2006;52(322):213-219.
12. de Sousa E, Rambo CR, Montedo ORK, Hotza D, Novaes de Oliveira AP. Porous glass ceramics of LZSA system using organic wastes as pore forming agent. Exacta. 2006;4(2):289296.

13. Machado RAF, Bolzan A, Quadri MGN, Oliveira PF, Schlischting R. Expanded polystyrene recycling and logistics chain structure. In: Proceedings of the $8^{\text {th }}$ Brazilian Congress on Polymers; 2005 Nov 6-10; Águas de Lindóia, SP, Brazil.

14. Mahabadi HK, Wright D. Semi-suspension polymerization process. Macromolecular Symposia. 1996;111(1):133-146.

15. Assis OB, Vieira DDC. Evaluation of crushed recycled glass as a filtration medium of agrotoxic materials in aqueous media. Revista Brasileira de Engenharia Agrícola e Ambiental. 2009;13(3):341-345.

16. Nagel A, Petzow G, Greil P. Rheology of aqueous silicon nitride suspensions. Journal of the European Ceramic Society. 1989;5(6):371-378.

17. Beach MW, Rondan NG, Froese RD, Gerhart BB, Green JG, Stobby BG, et al. Studies of degradation enhancement of polystyrene by flame retardant additives. Polymer Degradation and Stability. 2008;93(9):1664-1673.

18. McNeill IC, Razumovskii LP, Gol'dberg VM, Zaikov GE. The thermo-oxidative degradation of polystyrene. Polymer Degradation and Stability. 1994;45(1):47-55.

19. Jansen JAJ, Van Der Maas JH, De Boer AP. Hyphenated On-The-Spot TG/FT-IR Technique. Applied Spectroscopy. 1992;46(1):88-92.

20. Peterson JD, Vyazovkin S, Wight CA. Kinetics of the Thermal and Thermo-Oxidative Degradation of Polystyrene, Polyethylene and Poly(propylene). Macromolecular Chemistry and Physics. 2001;202(6):775-784.

21. Navarro JMF. El vidrio. $2^{\text {a }}$ ed. Madrid: Consejo Superior de Investigaciones Científicas. Fundación Centro Nacional del Vidrio; 1991.

22. Dias GMV, Arcaro S, Cesconeto FR, Maia BGO, Raupp-Pereira F, Novaes de Oliveira AP. Production and characterization of glass foams for thermal insulation. Chemical Engineering Transactions. 2015;43:1777-1782. 